\title{
Evolución en los principios de contabilidad de la deuda pública y sus impactos en la gestión del endeudamiento público en América Latina
}

Jairo Alonso Bautista

Recibido: 17 de marzo de 2014

Aprobado: 20 de mayo de 2014

Bautista, J. (2014). Evolución de los principios de contabilidad de la deuda pública y sus impactos en la gestión del endeudamiento público en América Latina. Activos 22, 79-108

Clasificación JEL: M48

\section{Resumen}

El ambiente de «normalidad» o de superación de la problemática de la deuda pública en los países latinoamericanos obedece no solo, y quizás no principalmente, a la aplicación de las medidas de ajuste desde los años 80 , sino al uso de nuevas formas de medir, valorar y representar la deuda pública. Este documento expone los principales cambios que se han presentado en los manuales de gestión de la deuda pública, en el ámbito de la contabilidad

1 Contador público, Universidad Nacional de Colombia. Magíster en Administración Pública, Escuela Superior de Administración Pública. Docente investigador de la Universidad Santo Tomás. Correo electrónico: jairobautista@usantotomas.edu. co. Grupo de investigación Contaduría: control y gestión de la información en las organizaciones. 
de la deuda pública, y que se han adoptado en diferente medida por parte de los países de la región.

El objetivo del documento es presentar un análisis sobre las formas específicas en que las orientaciones en materia de contabilidad de la deuda han incidido en los indicadores de deuda y, por ende, han reorientado el marco de gestión del endeudamiento público. Estos cambios han sido promovidos por los organismos financieros internacionales (OFI) como parte de las recomendaciones que ellos buscan implementar en los diversos países en materia de gestión de la deuda.

El artículo recurre a una presentación analítica sobre los principales lineamientos que han dominado la contabilización de la deuda pública en los sistemas de contabilidad fiscal en los últimos treinta años, la forma como estos han evolucionado y las consecuencias potenciales sobre los indicadores de deuda.

\title{
Palabras clave
}

Contabilidad pública, deuda pública, sistemas contables, política fiscal.

\section{Bautista, J. (2014). Changes in accounting principles of public debt and its impact on the management of public debt in Latin America. Activos 22, 79-108}

\begin{abstract}
The atmosphere of "normalcy " or overcoming the problem of public debt in Latin American countries, due not only (and perhaps not primarily) the implementation of adjustment measures since the 80s, but the use of new forms of measure, value and represent the public debt. The paper presents the main changes that have occurred in the operating management of public debt in the field of accounting and public debt have been adopted to varying degrees by the countries of the region.
\end{abstract}


The objective of the paper is to present an analysis of the specific ways in which the guidelines on accounting for debt have affected debt indicators, and therefore reoriented under management of public debt. Furthermore these changes have been promoted by the International Financial Institutions (OFI) as part of the recommendations seek to implement them in the various countries in debt management.

Uses an analytical presentation on the main lines that dominate the accounting for debt in fiscal accounting systems in the last thirty years and how these have evolved and the potential consequences on debt indicators.

\section{Keywords}

Public accounting, public debt, accounting systems, tax policy.

\section{Bautista, J. (2014). Lévolution des principes de comptabilité de la dette publique et son impact sur la gestion des capacités de engagement publique en Amérique Latine. Activos 22, 79-108}

\section{Résumé}

Latmosphère de «normalité» ou de résolution du problème de la dette publique dans les pays latino-américains est due non seulement, et peut-être pas principalement à la mise en œuvre des mesures d'ajustement depuis les années 80 , mais à l'utilisation de nouvelles méthodes de mesurer, évaluer et représenter la dette publique. Ce document présente les principaux changements qui sont survenus dans la gestion opérationnelle de la dette publique, dans le domaine de la comptabilité de la dette publique, et qui ont été adoptés à des divers degrés par les pays de la région.

Le but de ce document est de présenter une analyse des manières spécifiques dont directives comptables sur les indicateurs de la dette ont influencé la dette et donc ont recentré le cadre de la gestion de la dette 
publique. Ces changements ont été promus par les institutions financières internationales (OFI) dans le cadre des recommandations en cherchent à les mettre en œuvre dans les différents pays en matière de gestion de la dette.

Larticle se fonde sur une présentation analytique sur les principales lignes qui ont dominé la comptabilisation de la dette publique dans le système de comptabilité fiscale dans les trente dernières années, comment elles ont évolué et l'impact potentiel sur les indicateurs de la dette.

\section{Mots clés}

La comptabilité publique, la dette publique, les systèmes comptables, la politique budgétaire. 


\section{Introducción}

La deuda pública, o deuda soberana, se ha convertido en años recientes en una variable «bajo control» para los países de la región. Los sucesos que acompañaron las crisis de la deuda externa de los años 80 y las sucesivas crisis financieras de 1995, 1997 y 2001, que trajeron una nueva ola de inestabilidad económica y una nueva «dificultad de la deuda», parecen haber sido cosa del pasado, luego de que los gobiernos de la llamada «nueva izquierda latinoamericana» tomaran el poder en buena parte de los países dela región. Hoy estos fenómenos hacen mella en las estructuras fiscales de los países periféricos de Europa -los denominados PIGS $^{2}$ - y en los mismos Estados Unidos, por lo cual, parece que las políticas de gestión y control de la deuda pública en América Latina sirven como matriz de experiencias para su aplicación en los nuevos contextos de crisis de la deuda pública.

La CEPAL (2007) señala que las economías de la región habían retomado una senda de estabilidad en un escenario de alta perturbación global. Con el desarrollo de una crisis en los países centrales, que ha terminado por llevar a una cesación de pagos o default a varios de ellos en este nuevo contexto de crisis económica de los países centrales, América Latina se percibe como una región apacible donde los capitales están a buen refugio, además, sin problemas fiscales a la vista, o por lo menos no en los grandes de la región, y especialmente con niveles de deuda pública «sostenibles», lo que en un argot menos técnico significa que es una deuda que se paga cumplidamente.

Una primera revisión indica la falsedad de dichas percepciones: la región aún no ha logrado disminuir los niveles de pobreza e indigencia que mostró durante las décadas de los años 50 a 70 del siglo pasado; los niveles promedio de desempleo para 2011 se ubicaban en el 8,15\% en promedio, lo cual es casi un $30 \%$ más que el promedio presentado tres décadas atrás; y lo más significativo, la región convive con una deuda global que a principios del siglo XXI superaba ligeramente los niveles alcanzados durante los años 80 como proporción del PIB (43,3 \% en 1985 vs. 42,2 \% en 2010)

2 Portugal, Irlanda, Italia, Grecia y España. 
y una deuda real que superaba los 500000 millones de dólares en 2001, y que se acercaba al billón de dólares en 2008, lo cual contrasta con los años 80, cuando la deuda real llegaba apenas a los 500000 millones de dólares (Carrera, 2004; CEPAL, 2007).

Por lo tanto, cabe plantearse como pregunta central de este documento ¿cómo en un contexto de crisis social signada por el desempleo, la desigualdad en la distribución del ingreso y un aumento en los stocks reales de deuda pública que presionan por valiosos recursos fiscales para honrar las deudas, se percibe una situación de bajo riesgo o de control del endeudamiento y un ambiente de aparente superación del conflicto de la deuda? De este interrogante surgen otros: ¿cómo ha logrado entonces América Latina alejarse de una crisis de cesación de pagos, con unos niveles de deuda notoriamente superiores a los alcanzados en los años 80 ? ¿Qué ha implicado esta situación en materia de políticas públicas y de garantía de derechos sociales para los habitantes de los países de la región?

El objetivo del presente trabajo no es otro sino señalar que una parte de esta sensación de «tranquilidad» es resultado de los cambios de mediciones y valoraciones de la deuda en lo que compete a los sistemas de contabilidad de la deuda pública, cambios que han sido ideados y promovidos en el seno de los organismos financieros multilaterales y que se han implementado de manera acrítica en buena parte de los países de la región.

El análisis parte de una perspectiva crítica que se inscribe en el diagnóstico de la financiarización, es decir, desde la idea de que las sociedades y sus organizaciones políticas y económicas están sujetas a los intereses de la poderosa clase financiera internacional, y que en el caso de la deuda, los mecanismos, las técnicas de medición y la revelación de la información sobre la deuda, el sistema de estadísticas, los principios de gestión, etc. están encaminados a garantizar la reproducción del capital financiero, lo cual implica que la relación acreedor-deudor no sea una relación económica entre iguales, sino que supone un poder político concreto por parte del acreedor, el cual hace valer mediante una serie de instituciones de carácter global. 
En este sentido, el presente documento no abordará un diagnóstico sobre el estado actual de la deuda latinoamericana, pues otros trabajos (recomendamos unos pocos: Carrera, 2004; CEPAL, 2006; CIASE, 2008) han hecho balances sobre el comportamiento de la deuda pública en la región.

Por ende, este trabajo se concentrará en analizar las definiciones que sobre deuda y acerca de sus clasificaciones contables y estadísticas han emitido los Organismos Financieros Internacionales (OFI), y que han permitido una especie de manipulación de las categorías conceptuales de la deuda, en orden a disminuir su magnitud aparente y permitir a los países que adoptan tales definiciones endeudarse más, a la vez que mantienen niveles de pagos del servicio de la deuda «sostenibles», situación que genera un clima de confianza y tranquilidad para los mercados financieros, pero que oculta profundos problemas en las estructuras de financiamiento de los países.

\section{Las grandes tendencias del endeudamiento público en América Latina (2000-2011)}

Uno de los elementos más importantes en la descripción de los movimientos de gestión de la deuda pública en la última década la constituye la supuesta «eficacia» de las medidas de ajuste fiscal implementadas, que conllevó al control y a la esterilización de la deuda como un problema central de las finanzas públicas.

Otras de las grandes tendencias son la pérdida de protagonismo del financiamiento externo y el aumento de la deuda interna en la estructura de financiación de los Estados latinoamericanos. En realidad, esta es una percepción errónea, porque la mayor parte de la deuda interna proviene de instituciones financieras privadas que, si bien tienen asiento y representación en lo local, son en realidad subsidiarias o sucursales de poderosas casas financieras internacionales. La mayoría de estos fondos prestables se han apalancado con recursos de trabajadores y la ciudadanía en general por medio de la privatización de los fondos de pensiones 
y salud, o bien, gracias a los excedentes financieros que arrojaron las empresas privatizadas en la década de los 90 , estrategias todas que formaron parte de las reformas orientadas, supuestamente, a restablecer el equilibrio fiscal de los Estados.

Es muy diciente de este nuevo estado de cosas la publicación en 2007 del documento del BID titulado Living with debt, cuya propuesta central consiste en señalar la importancia de aprender a convivir con la deuda como un elemento siempre presente en la política fiscal de los Estados, un discurso que contrasta con los imperiosos llamados de unos años atrás para eliminar y reducir al máximo los stocks de deuda pública. Aprender a vivir con la deuda implica, entonces, un cambio en el paradigma de la gestión fiscal y el señalamiento de la necesidad de implementar políticas orientadas a garantizar la sostenibilidad de la deuda pública. Esto supone la adopción de nuevos procesos de reforma fiscal, como la creación de reglas fiscales, leyes que señalan en el ámbito constitucional o en el supralegal los límites máximos del gasto público a partir de una programación del déficit fiscal esperado, el cual dependerá fundamentalmente de la capacidad de endeudamiento de la economía.

Pero es también política la respuesta que se ha dado a este fenómeno, paralelo al crecimiento de los niveles de deuda. Debido a los perjuicios que causó en la ciudadanía la estructura fiscal que estaba en crisis recurrente como consecuencia del servicio de la deuda pública, se fueron gestando movimientos sociales locales, nacionales y posteriormente globales, que reclamaron la injusticia de las deudas y fueron construyendo un discurso alternativo que reivindica los derechos de los pueblos por encima de los derechos de los acreedores. Estos movimientos han logrado ciertas reivindicaciones en la escena de las políticas públicas y han visibilizado los aspectos desconocidos del endeudamiento soberano de los Estados latinoamericanos.

Las categorías y los conceptos que estos movimientos han construido para oponerse al predominio de los intereses de los acreedores financieros ocupan hoy un lugar importante en el panorama de debate sobre la deuda. 
Incluso los OFI han considerado la necesidad de crear grupos de pensamiento que busquen atajar los alcances políticos de estas iniciativas o, por lo menos, morigerar sus efectos. Esta realidad da idea de la trascendencia que estos movimientos «alternativos» han alcanzado, aunque aún están en una etapa primaria de acción política y sus logros han sido modestos si se les compara con el tamaño que obtienen las imposiciones y los condicionamientos impuestos por el endeudamiento público. Estos debates han impulsado el desarrollo de una corriente de opinión que pone en duda la legalidad y especialmente la legitimidad de las deudas, así como también la preeminencia que el «saber convencional» (Lo Vuolo, 2001) le otorga a la deuda en las definiciones centrales de la política fiscal.

Los OFI han emitido entonces una serie de disposiciones para el manejo del déficit fiscal, las cuales van desde las definiciones de déficit, las formas de medirlo y la determinación de las necesidades de financiamiento, hasta el manejo presupuestal que debe darse para la gestión del déficit fiscal.

\section{Banco Mundial y Fondo Monetario Internacional: recomendaciones para la contabilización y el análisis de la deuda}

Los OFI indican que los programas de ajustes fiscales se consideran más efectivos cuando se enmarcan dentro de un programa financiero acordado entre las autoridades. En la práctica, los programas financieros usan una estructura contable que totaliza todas las transacciones económicas y las interrelaciones entre los sectores. Para la contabilidad de la deuda, esto implica la adopción de unos patrones de contabilización de los pasivos que señalen, además de la posición de endeudamiento, el impacto macroeconómico de los flujos de deuda, el cual se describe a continuación. 
Tabla 1. Sistema de cuentas macroeconómicas

\begin{tabular}{lll}
\hline \multicolumn{1}{c}{$\begin{array}{c}\text { Sectores } \\
\text { macroeconómicos }\end{array}$} & \multicolumn{1}{c}{$\begin{array}{c}\text { Cuentas } \\
\text { macroeconómicas }\end{array}$} & \multicolumn{1}{c}{$\begin{array}{c}\text { Flujos de fondos } \\
\text { (transacciones) }\end{array}$} \\
\hline Sector privado & Cuentas nacionales & $\begin{array}{l}\text { Real: ingresos, gastos } \\
\text { Gobierno }\end{array}$ \\
Sector monetario & Cuentas fiscales & Cuentas monetarias $\mathrm{X}, \mathrm{M})$. \\
\hline Resto del mundo & Balanza de pagos & $\begin{array}{l}\text { Financiero: cambios } \\
\text { en los activos y pasivos } \\
\text { financieros. }\end{array}$ \\
\hline
\end{tabular}

C: consumo, S: ahorro, I: inversión, X: exportaciones, M: importaciones

Fuente: FMI, 2005.

De acuerdo con el FMI (1986, p. 10):

Los programas de ajuste consisten en conjuntos de medidas económicas de cobertura general destinados a alcanzar amplias metas macroeconómicas, como la mejora de la balanza de pagos, una mayor utilización del potencial productivo y el aumento de la tasa de crecimiento económico a largo plazo.

Sin embargo, el objetivo prioritario de tales programas se centra en corregir los desequilibrios de la balanza de pagos al cual se atan los demás objetivos, tales como lograr tasas óptimas de crecimiento del producto, utilizar el potencial productivo, etc. Estos son objetivos intermedios que se han de cumplir para poder conseguir el objetivo final, que es el equilibrio de la balanza de pagos. Los principales instrumentos de política a los que se recurre son la política fiscal y la monetaria.

Los voceros de la Institución manifiestan que los programas de ajuste respaldados por el FMI se diseñan «de acuerdo con un enfoque ecléctico» ${ }^{3}$

3 Cursivas añadidas. 
y no sobre una «única escuela del pensamiento económico», y que el hecho de que las políticas fiscal y monetaria tengan un papel central dentro de los programas de ajuste a efectos de equilibrar la balanza de pagos «no supone que los programas respaldados por el Fondo tengan necesariamente un carácter monetarista» (FMI, 1986, p. 86). Este enfoque ecléctico también implica un análisis contable de las categorías de representación de la deuda pública, el cual se describe a continuación.

\section{Un formato para el análisis contable del endeudamiento público}

La propuesta analítica de los OFI, en términos de la identificación contable de la deuda, parte de un conjunto de aseveraciones básicas, identificando la relación entre activos y pasivos del sector público.

Dentro de los activos están los siguientes: 1) los activos extranjeros, que analíticamente se entienden como los activos extranjeros netos. 2) Así mismo, dentro de estos activos están los activos internos compuestos por crédito del sector público, crédito de otras instituciones financieras y crédito del sector privado. 3) Finalmente se encuentran otros activos, entendidos analíticamente como otros activos netos.

Respecto de los pasivos se encuentran 1) los pasivos extranjeros (deuda externa), que se clasifican en corto plazo y se relacionan analíticamente con los activos extranjeros netos; también están los pasivos de mediano y largo plazo, entendidos analíticamente desde la estructura de otros activos netos. 2) En segundo lugar están los depósitos del sector público, 3) los depósitos del sector privado, 4) otros pasivos y 5) el capital y las reservas.

Esto implica el desarrollo de una serie de interrelaciones macroeconómicas, las cuales cuentan con los siguientes elementos:

- consumo, público y privado; 
- inversión interna bruta, pública y privada;

- exportaciones e importaciones de bienes y servicios;

- producto interno bruto;

- factor de ingreso neto;

- transferencias corrientes netas e

- ingresos brutos nacionales disponibles.

Las operaciones del sector público no financiero se componen de:

- ingresos y concesiones totales;

- gastos y préstamos netos totales: gastos corrientes, pago de salarios, bienes y servicios e intereses;

- gastos de capital o formación de capital fijo;

- balance total y

- financiamiento interno y externo.

La balanza de pagos se compone de:

- cuentas corrientes: exportaciones e importaciones de bienes y servicios, factor de ingreso neto y transferencias corrientes netas;

- cuentas de capital y financieras: inversión directa, financiamiento externo neto (sector público no financiero, sector privado no financiero y bancos) y

- cambios de las reservas netas internacionales. 
El estado bancario (flujos) se compone de:

- activos extranjeros netos del Banco Central y del resto del sistema bancario;

- activos internos netos: crédito doméstico neto (sector público no financiero y sector privado) y

- otros activos netos: deuda externa de mediano y largo plazo.

De esta manera, «el consumo público de las cuentas nacionales guarda relación directa con los pagos de salarios y bienes y servicios de las operaciones del SPNF, así como la inversión interna bruta de las cuentas nacionales con gastos de capital o formación de capital fijo de las operaciones del SPNF》 (FMI, 2005, p. 97).

De la misma forma, «los intereses correspondientes a las operaciones del SPNF se relacionan con el factor de ingreso neto de la balanza de pagos, y tanto el financiamiento interno y externo de las operaciones del SPNF con el financiamiento externo neto de la balanza de pagos» (Ibíd., p. 103).

Así, el financiamiento interno propio de las operaciones del SPNF guarda relación con el crédito interno neto del estado bancario. En este último también se encuentra el Banco Central, el cual se relaciona con el cambio de las reservas netas internacionales del estado bancario. También en este estado se hallan otros bancos que tienen relación con el resto del sistema bancario y con la deuda externa de corto y mediano plazo, componentes del estado bancario.

Esto genera un sistema de clasificación y medición de la deuda que ha sido introducido paulatinamente mediante la renovación de los manuales de gestión de la deuda, particularmente en la sexta versión del Manual de estadísticas de las finanzas públicas (FMI, 2001a). 


\section{Diferentes definiciones de la deuda pública}

Un primer campo de transformaciones ha sido provisto por las diferentes formas de definir la deuda pública. A continuación se presentan los elementos constitutivos de estas medidas.

\section{Deuda bruta}

Es el valor nominal de todas aquellas deudas del sector público no financiero (SPNF) que están en manos de agentes privados y/o públicos dentro y fuera del país. Es la suma horizontal de todas las deudas de las entidades no financieras que componen el sector público. Asimismo, se entiende que la DB pública incluye la deuda del GNC en cualquier tipo de bonos (por ejemplo: TES A y B; bonos Ley 546 y TRD; bonos de paz, seguridad, agrarios; bonos Fogafín, etc.), los bonos colocados por los municipios, las deudas de las entidades públicas de todos los niveles con el GNC (pagarés, acuerdos de pago y créditos presupuestales), las deudas (cartera) de todos los niveles del SPNF con el sector financiero (público y privado) y el rezago presupuestal de todas las entidades de todos los niveles. También incluye la deuda con los mercados internacionales de títulos con los bancos multilaterales y con proveedores externos

\section{Deuda neta de obligaciones intrapúblicas (DNOP)}

Es la deuda bruta descontando todas aquellas deudas entre entidades del mismo sector público. Esta es una definición de deuda mucho más utilizada porque permite saber cuánto le debe el sector público no financiero al resto de la economía; es la definición de deuda asumida por el Fondo Monetario Internacional para la comparación internacional y sobre la cual se hacen las proyecciones de sostenibilidad.

Esta definición no tiene en cuenta la existencia de activos financieros en manos del sector público, como consecuencia, los análisis de solvencia se distorsionan, de manera que no es posible diferenciar si la financiación del 
déficit se hace reduciendo el nivel de activos financieros del sector público o aumentando la DNOP.

\section{Deuda neta de activos financieros (DNAF)}

Es la DNOP luego de descontar todos aquellos activos financieros (CDT, bonos, fondos públicos, portafolios en el exterior) en manos del SPNF. La definición en cuestión se aproxima a un concepto de patrimonio neto, ya que utiliza una parte del lado del activo de los balances de las entidades públicas.

El impacto de las diferentes definiciones de deuda es visible en la figura 1.

Figura 1. Diferentes definiciones de deuda pública

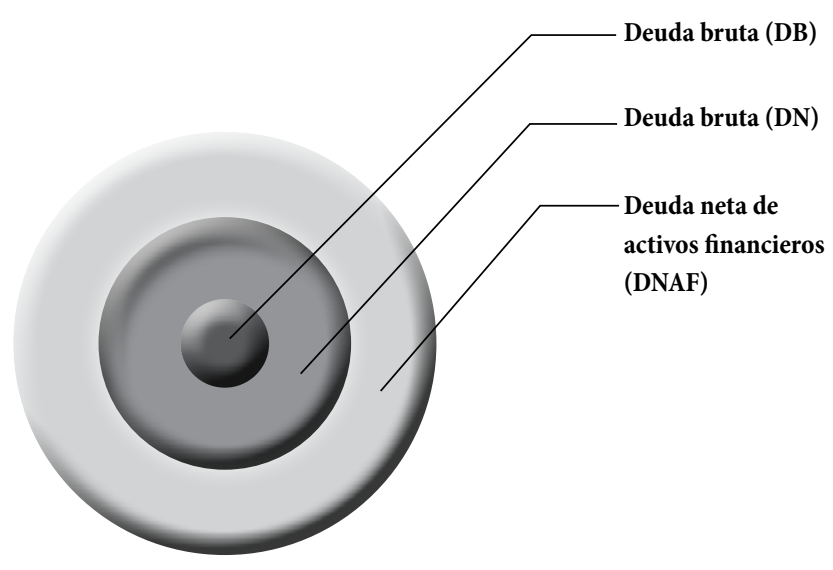

Fuente: CONFIS, 2002.

\section{Deuda pública cierta y deuda contingente}

Otra forma de clasificar la deuda pública es dividiéndola entre deuda cierta y deuda contingente. Para ello es necesario establecer conceptualmente qué implica cada uno de estos tipos de deuda. 
Según Clavijo (2003, p. 3):

La principal diferencia conceptual entre la deuda pública cierta y la deuda contingente es que sobre la primera se pagan intereses en atención a una regla acordada previamente (bien sea a tasa fija $o$ a tasa flotante, bien sea en moneda nacional o moneda extranjera). No obstante, el resultado final de lo que representa dicho costo financiero sobre la deuda cierta tampoco puede conocerse ex-ante, pues sus determinantes están afectadas por la política monetaria, la cambiaria y las interrelaciones de estos mercados con el gasto público.

La deuda pública cierta incluye al SPNF, esto es, la suma de las deudas del gobierno nacional central (GNC), de los municipios y departamentos, de las entidades descentralizadas, las empresas públicas y los establecimientos públicos, en todos los casos, de todos los niveles. La sostenibilidad de la deuda se mide con la deuda pública cierta, la cual está representada por la deuda externa e interna desembolsada al sector público.

Según Clavijo (2003), es posible establecer el costo real de servir dicha deuda en el futuro, mediante la asignación de una tasa de interés real y suponiendo otros valores macroeconómicos. Esta deuda es aquella que ha sido efectivamente desembolsada a las entidades públicas y, por lo tanto, constituye ya un pasivo del Estado con el prestamista. Se pagan intereses en atención a una regla acordada previamente (bien sea a tasa fija o a tasa flotante, bien sea en moneda nacional o moneda extranjera). En el sistema de cuentas individuales, que prevalece en el sector privado, la tasa de interés juega un papel directo y determinante.

Por su parte, la deuda pública contingente incluye el pasivo pensional, los bonos de apoyo al sistema financiero o las garantías públicas extendidas en los proyectos de riesgo compartido con el sector privado. El costo de esta deuda vendrá determinado por otros factores especíicos a dichas áreas, como son los factores demográficos, los del sector financiero, los del tráfico vehicular, energético y de telecomunicaciones. Está sujeta a la ocurrencia de algún evento antes de registrarla como tal, por ejemplo, la deuda pensional. 
Las tasas de interés afectarán también la viabilidad de honrar estas deudas, pero esto ocurre de manera indirecta en la medida en que el Estado deba endeudarse para honrar esos compromisos. Las pensiones dependen exclusivamente de los aportes y de sus rendimientos acumulados.

Según Daniel et al. (2006, p. 34),

El pasivo contingente consiste en obligaciones financieras desencadenadas por determinados acontecimientos, no es fácil de recoger en las estadísticas y análisis fiscales estándares. Existen dos categorías principales de pasivo contingente: el que vence si se materializan determinados acontecimientos, como el impago de deuda garantizada por el gobierno que, por lo tanto, este tiene que asumir; y el que se deriva del compromiso implícito o "moral" del gobierno, por ejemplo, de proteger a los depositantes en caso de la quiebra de un banco o de abonar las pensiones en el caso de que un plan de pensiones vaya a quiebra. (...) el pasivo contingente es una subvención oculta, empaña el análisis fiscal y puede consumir las finanzas públicas futuras.

La importancia de diferenciar la deuda cierta de la contingente es la posibilidad de distinguir en la formulación de la política de endeudamiento, aquellos factores que pueden demandar una cantidad no conocida de recursos para hacer frente a una exigencia concreta en un periodo determinado.

Calcular la deuda contingente implica asimismo analizar la probabilidad de que estas exigencias se concreten y pasen a ser deudas ciertas; esto depende fundamentalmente de las políticas establecidas en la materia.

En este sentido, una de las deudas contingentes de mayor importancia es la pensional, en la medida en que las deudas asumidas en el modelo de prima media pueden variar al tenor de las reformas establecidas en el régimen pensional. La incertidumbre no es solo para quien debe pagar la deuda asumida, sino para los potenciales acreedores del gobierno, es decir, los pensionados. 


\section{Estructura y clasificación de la deuda pública}

La estructura de la deuda puede ser una fuente importante de vulnerabilidad y riesgo. Por ejemplo, cuando la deuda pública es a corto plazo, está indexada a tasas de interés a corto plazo o vinculada a divisas extranjeras. Las presiones en los mercados monetario y de divisas extranjeras pueden traducirse rápidamente en problemas para el servicio de la deuda. El «enfoque del balance», que examina los vínculos entre los balances de los diversos sectores de la economía, puede ayudar a detectar vulnerabilidades y presiones potenciales derivadas de estos. Con ello, la deuda pública se puede clasificar así:

\section{Deuda interna y externa}

En esta clasificación se entiende la deuda pública adquirida por origen. La deuda interna se considera aquella que se toma con agentes nacionales o extranjeros dentro del territorio nacional; es usualmente denominada en la moneda nacional. En otros términos, la deuda interna es la contratada dentro del país, se genera si es colocada en moneda local, en el mercado local y es comprada por residentes del país.

La deuda externa se toma con agentes extranjeros o nacionales fuera del territorio nacional y se denomina en divisas. La deuda externa se contrata fuera del país. Bolívar aduce que este tipo de deuda se presenta si es colocada en el exterior, en moneda extranjera y es comprada por residentes del resto del mundo.

Los recursos de cada una de estas deudas pueden provenir de las siguientes fuentes:

Para el caso de la deuda interna, los títulos de tesorería (TES) son títulos valores emitidos por el gobierno, con un plazo y una tasa de interés determinada para financiar actividades generales del presupuesto; así mismo, para financiar este tipo de deuda se encuentran los préstamos bancarios del sistema financiero privado, el crédito de proveedores y el préstamo del Banco 
Central, estos últimos entendidos como la emisión primaria de dinero para financiar el déficit del gobierno.

En el caso de la deuda pública externa, la fuente de financiación puede provenir de la emisión de bonos, la cual se denomina usualmente en dólares; también existe el préstamo con la banca multilateral, destacándose históricamente el Banco Mundial (BM), el Banco Interamericano de Desarrollo (BID), la Corporación Andina de Fomento (CAF) y el Fondo Latinoamericano de Reservas. La naturaleza del Fondo Monetario Internacional (FMI) es distinta de la de las demás entidades, dado que es una entidad que apoya los déficits de balanza de pagos.

De otro lado se encuentran los préstamos con banca comercial y los préstamos de los gobiernos extranjeros. Estos últimos usualmente se conocen como préstamos EXIMBANK, en los cuales los gobiernos condicionan el crédito a la compra de insumos y material de empresas de sus propios países. Estos créditos están orientados a promocionar la exportación de bienes y servicios de las empresas de las naciones prestamistas. Finalmente están los préstamos de proveedores, entendidos como los créditos comerciales que usualmente se encuentran en la compra de equipos militares que por decisiones políticas no son financiados por la banca multilateral ni por la banca comercial.

Sin embargo, a partir de estas perspectivas de financiamiento, existen dos casos especiales:

El crédito del Banco Central, encargado de regular las relaciones monetarias de un país. Es el encargado de determinar los niveles de oferta monetaria, las tasas de interés, de regular la inflación y las relaciones de la moneda nacional con las monedas extranjeras (política cambiaria). El Banco Central es una institución del gobierno, por ende, en principio su acción está delimitada por las políticas gubernamentales, así que cuando se presenta un déficit en la estructura fiscal del gobierno, este puede recurrir al Banco para que lo financie. 
El crédito de la banca multilateral se toma con organismos financieros internacionales que otorgan créditos sujetos a las políticas y los principios que desarrollan y definen. Los principales prestamistas multilaterales del país son el Banco Mundial (BM), que también se conoce como Banco Internacional de Reconstrucción y Fomento (BIRF), y el Banco Interamericano de Desarrollo (BID).

\section{Deuda pública por nivel territorial}

En este aspecto se incluye el sector público no financiero, que corresponde a una clasificación sectorial que reúne a todas las entidades cuya actividad sea no financiera, en los términos de la definición del Manual de estadísticas de las finanzas públicas ${ }^{4}$, de los niveles central, territorial y descentralizado el sector público. El SPNF es la unidad central de análisis del sector público en la medida en que se considera que la actividad financiera que emprenden algunas unidades institucionales del sector público (banca pública, fondos de promoción) no deben ser actividades centrales del gobierno ${ }^{5}$.

En otras definiciones, los controles de la deuda se hacen sobre el agregado del gobierno nacional central, que comprende a todas las unidades institucionales del nivel nacional en los términos definidos por el Manual de estadísticas de las finanzas públicas como aquellas que tienen funciones estrictamente de gobierno.

Otras clasificaciones territoriales atienden a la definición de la deuda del sector público consolidado. La Contraloría General de la República en Colombia y en general los organismos encargados del control fiscal macro atienden a esta definición. Esto implica que se contabilizan todas las deudas

4 La definición de sector financiero, según el Sistema de Cuentas Nacionales, se refiere a la intermediación de recursos entre agentes deficitarios (prestatarios) y agentes superavitarios (prestamistas). Esta misma definición se toma para la clasificación de las finanzas públicas.

5 Sin embargo, esta discusión pertenece al terreno de la economía política, sin que hasta el momento haya claridad sobre la verdadera naturaleza de tomar como eje del análisis fiscal al sector público no financiero. 
de todos los niveles de gobierno; en algunas definiciones, incluso se considera la deuda del Gobierno nacional con el Banco Central.

\section{Recomendaciones para la gestión de la deuda pública: incidencias contables}

El conjunto de recomendaciones para la gestión de la deuda parte de la necesidad de hacer reformas fundamentales en los elementos de medición y representación de la deuda, así como del ámbito territorial que en ella se refleja.

Según el FMI (2001, p. 13), gestionar la deuda «significa establecer una estrategia en la cual se obtenga un monto de financiamiento fijo y desarrollar y mantener un mercado eficiente para los títulos de deuda pública» ${ }^{6}$. Gestionar la deuda implica la compensación entre costos y riesgos. El costo de la deuda pública tiene dos componentes: el costo financiero, que corresponde al pago del servicio de la deuda a mediano y largo plazo, y el "costo potencial en pérdidas económicas reales que pudiera resultar de una crisis financiera si el gobierno tuviera dificultades para renovar la deuda o si incumple» (Ibíd.).

Pero justamente una forma de lograr estas compensaciones se basa en determinar claramente los montos de la deuda que afectarán los cálculos de sostenibilidad y los indicadores globales de endeudamiento. En el aspecto macroeconómico, el quehacer de los gobiernos y de la administración pública en general debe garantizar la sostenibilidad del nivel y de la tasa de crecimiento de la deuda pública, al mismo tiempo que debe responder ante unos objetivos determinados de costo y riesgo. La medición de la sostenibilidad de la deuda a nivel macroeconómico implica el uso de indicadores de coeficiente de servicio de la deuda del sector público: la relación entre

6 Los mercados de valores públicos permiten que el gobierno cuente con un mecanismo de financiación del gasto público, reduciendo de esa manera la opción de acudir al Banco Central para la financiación del déficit y reduciendo, a su vez, el costo del servicio de la deuda a corto y mediano plazo. 
deuda pública y PIB, deuda pública e ingresos tributarios, sumando a ello la gestión armónica entre la política fiscal y la monetaria ${ }^{7}$. Según el Banco Mundial (2008), si estas políticas actúan en conjunto y armónicamente, los riesgos en la estructura de tasas de interés a largo plazo son menores; en cambio, cuando existen medidas económicas inapropiadas en las políticas fiscal, monetaria y cambiaria, se afirma que existe una estructura arriesgada de endeudamiento. Cuando en estos tres campos se toman «medidas inapropiadas», se generan incertidumbres en los mercados financieros sobre la rentabilidad de las futuras inversiones.

Por ende, las crisis de la deuda se presentan

(...) debido a que los gobiernos han hecho excesivo hincapié en una posible reducción de costos mediante empréstitos en gran escala a corto plazo o tasa de interés variable. La consecuencia ha sido que el presupuesto público ha estado gravemente expuesto a los avatares de los mercados financieros, comprendido todo cambio en la capacidad crediticia del país, en el momento de renovar la deuda. (FMI, 2001b, p. 24)

También argumenta que:

Reduciendo el riesgo de que la gestión de la cartera del propio gobierno se convierta en fuente de inestabilidad para el sector privado, la gestión prudente de la deuda pública, unida a medidas acertadas sobre gestión de los pasivos contingentes, puede conseguir que los países sean menos vulnerables al contagio y el riesgo financiero. (FMI, 2001b, p. 24)

Lo que se busca establecer es una estructura adecuada de la deuda pública, de tal manera que los gobiernos puedan reducir riesgos como los asociados a las tasas de interés y la moneda (de mercado). Para lograrlo, y en la medida de las posibilidades, los gobiernos deben establecer puntos de referencia en la cartera para «la composición deseada de la moneda», así como la duración y estructura de los plazos de vencimiento de la deuda.

7 Para una mayor ilustración sobre los indicadores de deuda, ver el anexo 1. 
En conjunto, los principios de gestión de la deuda pública han trazado una serie de reformas contables en la medición y representación de la deuda pública, las cuales se pueden resumir en los siguientes elementos:

\section{Cambios en los ámbitos territoriales}

Hasta bien entrada la primera década de este siglo, los OFI acostumbraron poner como variable la deuda del Gobierno nacional de cada uno de los países donde operaban sus programas de asesoría y apoyo financiero. A partir de 2002, tanto el Banco Mundial como el Fondo Monetario Internacional, en los manuales de gestión de la deuda y en los acuerdos stand by suscritos por el FMI, cambiaron la definición por la de sector público no financiero, la cual incorpora las deudas de las empresas públicas y el efecto fiscal acumulado de los niveles subnacionales. A la larga, esto incidió en la baja del indicador de deuda, puesto que durante los años 80 del pasado siglo, las políticas de ajuste, impulsadas y defendidas nuevamente desde los OFI, llevaron a la nacionalización (centralización) de las deudas de las empresas públicas y, en general, de todo el nivel descentralizado, de tal manera que unos y otros contaban con excedentes fiscales netos a finales de los años 90, es decir, tenían ahorro en lugar de deuda.

\section{Cambios en la definición de 'deuda'}

La segunda gran transformación en la contabilidad de la deuda consistió en cambiar las definiciones tradicionales de deuda bruta (sumatoria de todas las deudas de todas las instituciones que componen bien sea el sector público no financiero o el Gobierno nacional). A mediados de los años 90, había un intenso debate entre las calificadoras de riesgo-país y los OFI sobre la definición más adecuada de deuda pública, que permitiera revelar la posición de endeudamiento más certera de un país.

Mientras los OFI, especialmente el FMI, recomiendan el uso de definiciones que permitan revelar la «posición financiera neta» del sector público 
-y, por ende, cambiar la revelación del concepto de deuda bruta por deuda neta de activos intrapúblicos (DNOP) con el fin de eliminar las deudas recíprocas entre entidades del mismo sector público-, las calificadoras de riesgo se han decantado por tomar la definición que revela un índice de deuda mucho más abultado, como es el de deuda bruta. Así, mientras que un país como Brasil, que para 2002 tenía un indicador de deuda bruta (o deuda no consolidada) del $70 \%$ del PIB -y, por tanto, reportado como un país en alto riesgo de cesación de pagos por calificadoras como Moody's-, revelaba un indicador de deuda neta de activos intrapúblicos del $50 \%$ del PIB y se convertía, para el FMI, en un país de gran estabilidad fiscal. Casos similares se presentaron en Colombia (deuda bruta del $75 \%$ del PIB y deuda neta de operaciones intrapúblicas de alrededor del $40 \%$ del PIB). (Martner \& Tromben, 2004).

A mediados de la década pasada, el departamento de estadísticas del FMI y el BID (BID, 2007) recomendaban usar un indicador diferente que reconociera no solo el «neto» de los pasivos intrapúblicos, sino además la necesidad de descontar las inversiones financieras en manos de instituciones del sector público: esto corresponde a la definición de deuda neta de activos financieros y, tal como señala el FMI (2001b), esto implica una aproximación a la definición de capital financiero neto para las unidades del sector público.

Estos cambios de definición tienen el impacto analizado en la sección correspondiente del presente documento, es decir, redujeron contablemente el monto de la deuda, muchas veces sin haber puesto atención sobre la fiabilidad de los activos en manos de las instituciones del sector público o su garantía, tema que no se analiza en el presente trabajo.

En general, aunque no existe un consenso en los países de la región sobre las formas más adecuadas de representar y revelar los montos de deuda, las múltiples posibilidades de interpretación y contabilización hacen que en muchos casos los indicadores que revelan los procesos de gestión de la deuda sean altamente cuestionados, aunque usualmente estos cuestionamientos 
raramente alcancen las dimensiones de un debate público amplio (para un ejemplo de estos debates, ver Strautmann, 2009).

\section{El debate sobre la deuda contingente}

Un elemento final que incide en el debate contable de la deuda pública es el dilema sobre la presentación de la deuda contingente en los balances de la deuda pública. La decisión de incorporar toda o una parte de esta es un tema de permanente polémica, inicialmente porque no hay un acuerdo sobre lo que es o no deuda contingente (los avales entregados por el gobierno para el endeudamiento de empresas públicas o entidades de niveles subnacionales, por ejemplo) o incluso sobre las técnicas y los instrumentos adecuados para calcular las deudas contingentes.

Algunas calificadoras de riesgo, así como el BID, han señalado en diferentes momentos la necesidad de incorporar parcialmente indicadores de deuda contingente, especialmente la que se adquiere a causa del pasivo pensional, la cual tiene un alto grado de compromiso o certeza. Sin embargo, no es clara la forma en que el cálculo de la deuda contingente afecta el balance de deuda del sector público.

\section{Conclusiones}

A pesar de no ser un tema de álgido debate en el marco de la política fiscal en América Latina, la deuda pública representa hoy un conjunto de desafíos para la gestión del Estado. Los indicadores de deuda revelan una situación de control que no se corresponde con el elevado monto de las deudas reales de los países de la región.

En este contexto, se ha desarrollado un amplio conjunto de propuestas sobre las formas de medir, contabilizar y revelar la deuda púbica, muchas de ellas orientadas a disminuir la presión de los indicadores globales de deuda. La nitidez de los debates alrededor de estos temas es escasa, pues estos temas rara vez adquieren relevancia en la opinión pública, menos 
cuando permiten que los gobiernos y las autoridades económicas puedan presentar situaciones positivas en este ámbito.

Falta aún mucha discusión sobre la conveniencia o inconveniencia de adoptar nuevas fórmulas sobre la medición y revelación de la deuda pública. Las reflexiones en este sentido son escasas y se basan en análisis superficiales, sin que existan hasta el momento estudios empíricos que permitan calcular el impacto de las redefiniciones contables de la deuda en el monto de esta o en el desarrollo de indicadores claves.

Es claro que en la última década los OFI han trabajado fuertemente para desplegar una serie de recomendaciones sobre contabilidad de la deuda, muchas de las cuales se han implementado en la contabilidad fiscal de buena parte de los países de la región. Sin embargo, la revelación de dichos cambios no constituye parte del acervo que se presenta en las estadísticas de las finanzas públicas, por tanto, esto imposibilita adelantar un estudio más detallado, el cual está en mora de hacerse, con el fin de establecer, como ya se señaló, el impacto real que sobre los niveles de endeudamiento público tienen los cambios contables descritos en el documento.

\section{Referencias bibliográficas}

Banco Mundial. (2008). Gestión de la deuda pública: del diagnóstico a la implementación de las reformas. Bogotá: Banco Mundial, Mayol Ediciones.

Banco Interamericano de Desarrollo. (2007). Vivir con la deuda: cómo contener los riesgos del endedamiento público. Nueva York: BID Recuperado de http:// goo.gl/ixmo8B.

Caballero, C. (2001). Una nota sobre la evolución, la estructura de la deuda pública y su implicación en el sistema financiero colombiano. Bogotá: Banco de La República.

Cañibano, L. (1987). Contabilidad: análisis contable de la realidad económica. Madrid: Ediciones Pirámide.

Carrera, M. (2004). La deuda externa en América Latina veinte años después: una nueva media «década perdida». Revista Investigación Económica, 247, 103-141. 
Castillo, I. (2010). Evolución histórica de la contabilidad pública. Documento presentado en el marco de la Segunda Cátedra Nacional en Contabilidad Pública «Edgar Nieto», Bogotá.

Clavijo, S. (2003). Deuda pública cierta y contingente. El caso de Colombia. En CEPAL (2003), Reglas macrofiscales, sostenibilidad y procedimientos presupuestarios: documentos presentados en el XV Seminario Regional de Política Fiscal. Santiago de Chile: CEPAL.

CEPAL. (2006). Situación de la deuda pública en América Latina. Informe anual. Santiago de Chile: CEPAL.

CIASE. (2008). Deuda externa y derechos humanos. Bogotá: CIASE.

Colciencias y Ministerio de Hacienda y Crédito Público. (2000). Proyecto Lectores del Presupuesto. Informe final. Bogotá: Gestión y Desarrollo Ltda. Recuperado de http://goo.gl/M0AOrH.

Comisión Económica para la América Latina. (2007). Panorama social de América Latina. Informe anual de la CEPAL. Santiago de Chile: CEPAL.

Consejo Nacional de Política Ficscal (Colombia) - CONFIS. (2002). La deuda pública colombiana: definiciones, estadísticas y sostenibilidad. Documentos Asesores, 2.

Daniel, J., Davis, J., Fouad, M., \&Van Rijckeghem, C. (2006). Ajuste fiscal para la estabilidad y el crecimiento. Washington: Fondo Monetario Internacional. Recuperado de https://goo.gl/tYruCi.

Esteves, J. L., Anaya, M. y Ceceña, J. L. (1983). La deuda pública en America Latina. Cuadernos. México D. F.: Instituto Doctor José María Luis Mora.

Fondo Monetario Internacional. (1986). Manual de estadísticas de las finanzas públicas (Versión 5). Washington: FMI.

Fondo Monetario Internacional. (2001a). Manual de estadísticas de las finanzas públicas (Versión 6). Washington, D. C.: FMI.

Fondo Monetario Internacional y Banco Mundial. (2001b). Directrices para la gestión de la deuda pública (Guidelines of Public Debt Management). Washington, D. C.: FMI y BM.

Fondo Monetario Internacional. (2003). Estadísticas de la deuda externa: guía para compiladores y usuarios. Washington, D. C.: FMI.

Fondo Monetario Internacional. (2005). Sistema de cuentas financieras. Washington, D. C.: FMI. 
Fondo Monetario Internacional. (2007). El sistema de estadísticas de las cuentas macroeconómicas. Panorama general. Washington. , D. C.: FMI.

Giraldo, C. (2009). Finanzas públicas en América Latina: la economía política (2. ed.). Bogotá: Ediciones Desde Abajo.

Lichtensztejn, S., \& Baer, M. (1989). Fondo Monetario Internacional y Banco Mundial: estrategias y políticas del poder financiero. Caracas: Editorial Nueva Sociedad.

Lora, E. (2008). Técnicas de medición económica (4. . ed.). Bogotá: Alfaomega.

Lo Vuolo, R. (2001). Alternativas: la economía como cuestión social. Buenos Aires: Editorial Altamira.

Martner, R., \& Tromben, V. (2004). La sostenibilidad de la deuda pública, el efecto bola de nieve y el pecado original. Santiago de Chile: ILPES y CEPAL.

Ministerio de Hacienda y Crédito Público. (2005). Marco fiscal de mediano plazo. Bogotá: Imprenta Nacional.

Organización de las Naciones Unidas. (1993). Sistema de cuentas nacionales (Versión 1993). Washington, D. C.: ONU.

Sagasti, F. (2004). La Banca multilateral de desarrollo en América Latina. En J. A. Ocampo, A. Uthoff (Comp.), Gobernabilidad e integración financiera: ámbito global y regional (pp. 251-320). Santiago de Chile: Naciones Unidas-Comisión Económica para la América Latina (CEPAL).

Strautmann, G. (2009). Brasil: deuda pública. ¿Quién debe a quien? Revista Activos, $14,23-45$. 


\section{Anexo 1: Indicadores macroeconómicos relacionados con la deuda pública}

A continuación se presentan los indicadores más usados por los OFI en la gestión y el análisis de la deuda pública.

- Deuda externa y exportación. «Indicador útil de la tendencia de la deuda, estrechamente vinculado con la capacidad del país para rembolsar su endeudamiento».

\section{Dext / X}

- Deuda externa y PIB. «Indicador útil para relacionar la deuda con la base de recursos (refleja el potencial para transferir producción a la exportación o a la sustitución de importaciones con el fin de reforzar la capacidad de rembolso)».

\section{Dext / PIB}

- Promedio de las tasas de interés sobre la deuda externa. «Es un indicador útil de las condiciones del crédito obtenido. En conjunción con los coeficientes deuda/PIB y deuda/exportación, y con las perspectivas de crecimiento económico, constituye un indicador clave para evaluar la sostenibilidad de la deuda».

\section{i / Dext}

- Promedio de los vencimientos. «De utilidad para emplearlo con categorías homogéneas, como la deuda del sector público en condiciones no concesionarias, y para realizar el seguimiento del proceso de reducción de los plazos de vencimiento o las medidas encaminadas a reducir futuras vulnerabilidades».

\section{Vencimientos / Dext}


- Proporción total de la deuda externa que corresponde a deuda en moneda extranjera. «Es un indicador útil del impacto de la variación del tipo de cambio sobre la deuda (efecto balance), sobre todo si se une a información sobre los instrumentos derivados que modifican la composición efectiva de monedas».

\section{DExtdiv / Dext}

Pero hay que tener en cuenta que en el cálculo del nivel de sostenibilidad, algunas medidas recomiendan la inclusión de los pasivos no corrientes o pasivos contingentes, estos «representan títulos financieros potenciales frente al gobierno aún no realizados, pero pueden dar lugar a una obligación o un pasivo financiero firme en ciertas circunstancias» (FMI, 2001, p. 34):

- Garantías gubernamentales sobre los empréstitos en moneda extranjera obtenidos por ciertos prestatarios nacionales.

- Planes públicos de seguros.

- Opciones de venta sobre valores públicos.

- Rescate a entidades del sector financiero, empresas de propiedad pública y gobiernos regionales. 